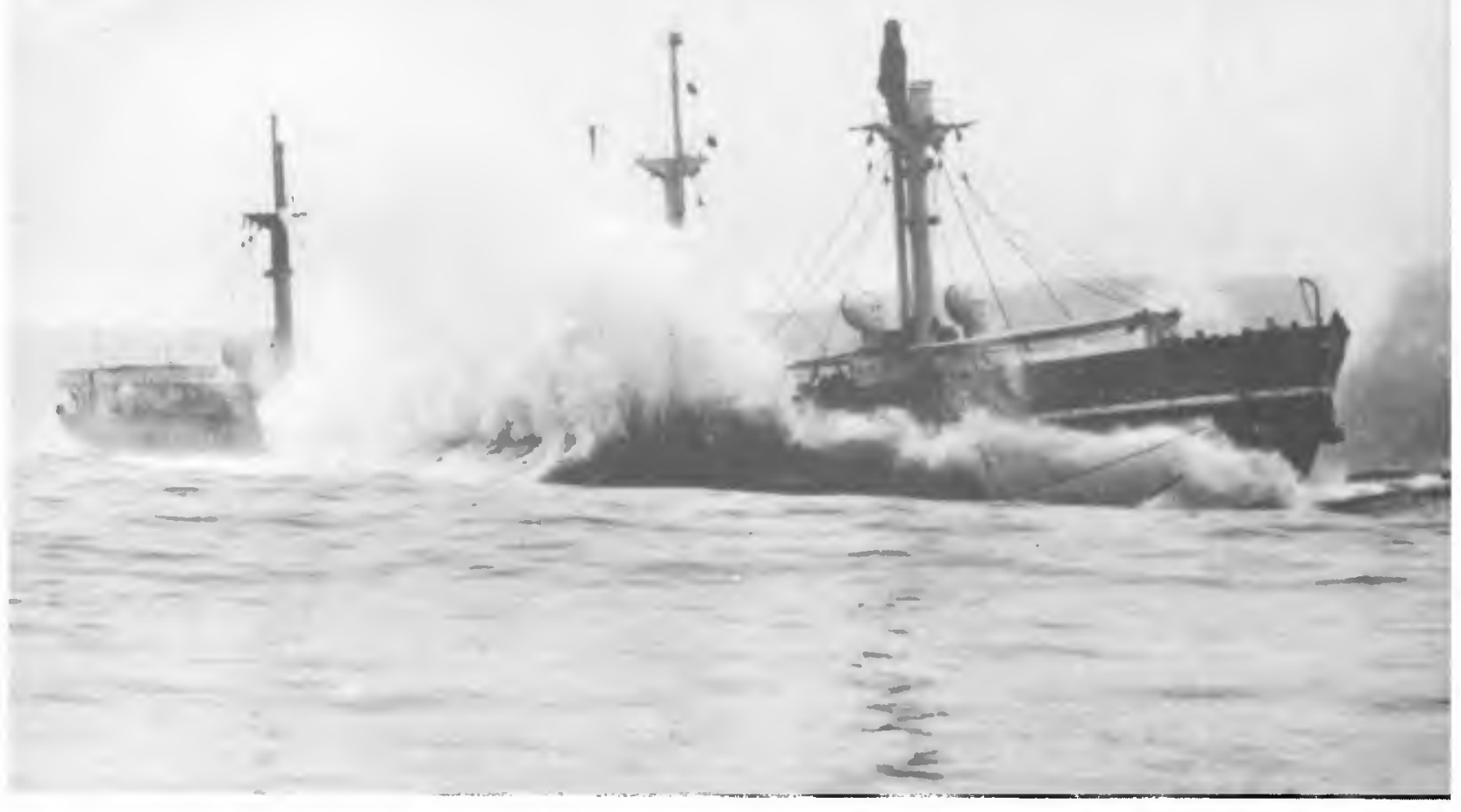

PART 1

BASIC INFORMATION FOR COASTAL INVESTIGATIONS

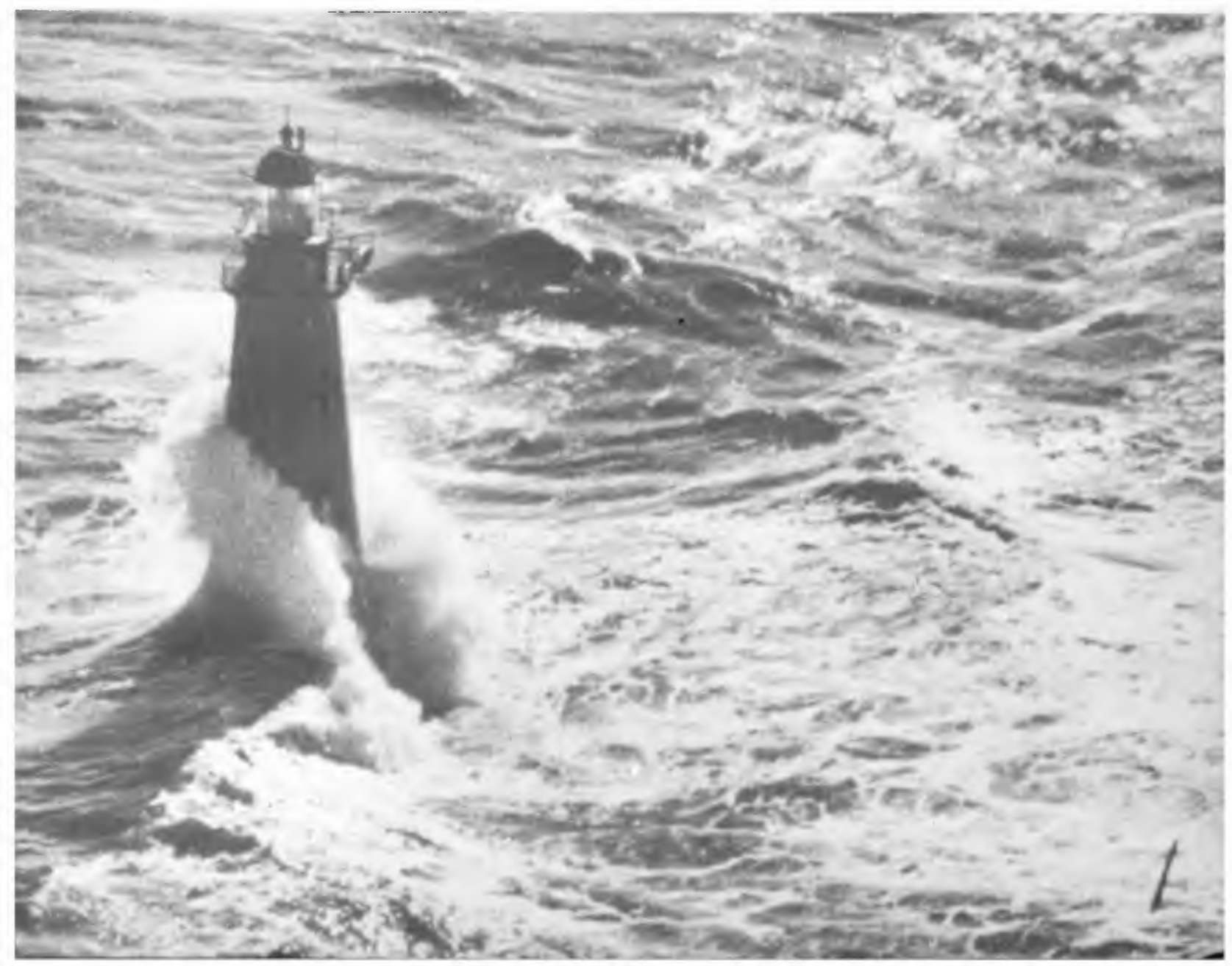





\title{
REVISED WAVE FORECASTING RELATIONSHIPS
}

\author{
C. I. Bretschneider* \\ Institute of Engineering Research \\ University of California \\ Berkeley, California
}

\section{INTRODUCTION}

Data on the generation and decay of wind-generated gravity waves have been collected for several years by the Oniversity of Califormia. These data together with the original data by sverdrup and sumk have been analyzed, and the results were presented in dimensionless graphs suitable for use in wave forecasting (Bretschneider, 1951). No analysis was made of the effect of following or opposing winds.

The dimensionless paraneters presented by Sverdrup and Munk (1947) $\left(c / U, g H / \tau^{2}, g F / \tau^{2}, g t / \tau\right.$, and $\left.t U / F\right)$ are suitable; however, new curves have been constructed which include the new data recently available (Figure 1). In order that the data on the decay of waves could be presented in a logical manner, a concept, based on the following observations was introduced: (a) Individual waves do not maintain their identity in deep water, (b) a spoctrum of lengths and heights is present in both the fetch and decay areas, (c) at any particular decay distance the significant period decreases with time, (d) the significant period increases with decay distance in a manner different then that assumed by Sverdrup and liunk for their decay relationships, (e) the travel time depends upon the group velocity associated with the period at the end of the decay distance.

It is found that the wave height and period at the end of the decay distance depend upon the length of the fetch and the height and period at the end of the fetch as well as upon the decay distance. Using $D / F$ as a dimensionless parameter, decay graphs, $\mathrm{D} / \mathrm{gT}_{\mathrm{F}}{ }^{2}$ versus $\mathrm{D} / \mathrm{gT}_{\mathrm{D}}{ }^{2}$ and $\mathrm{D} / \mathrm{H}_{\mathrm{F}}$ vers $\mathrm{D} / \mathrm{H}_{\mathrm{D}}$, were constructed representing the increase of period and the decreas in height, respectively. These curves give a unique solution for each combination of period and height at the end of the fetch; whereas, the decay relationships proposed by Sverdrup and liunk (1947) gave a unique solution for the increase of wave period regardless of the wave height at the end of the fetch.

\footnotetext{
* Now Research Engineer with Texas A \& M Research Foundation, College Station, Texas
} 


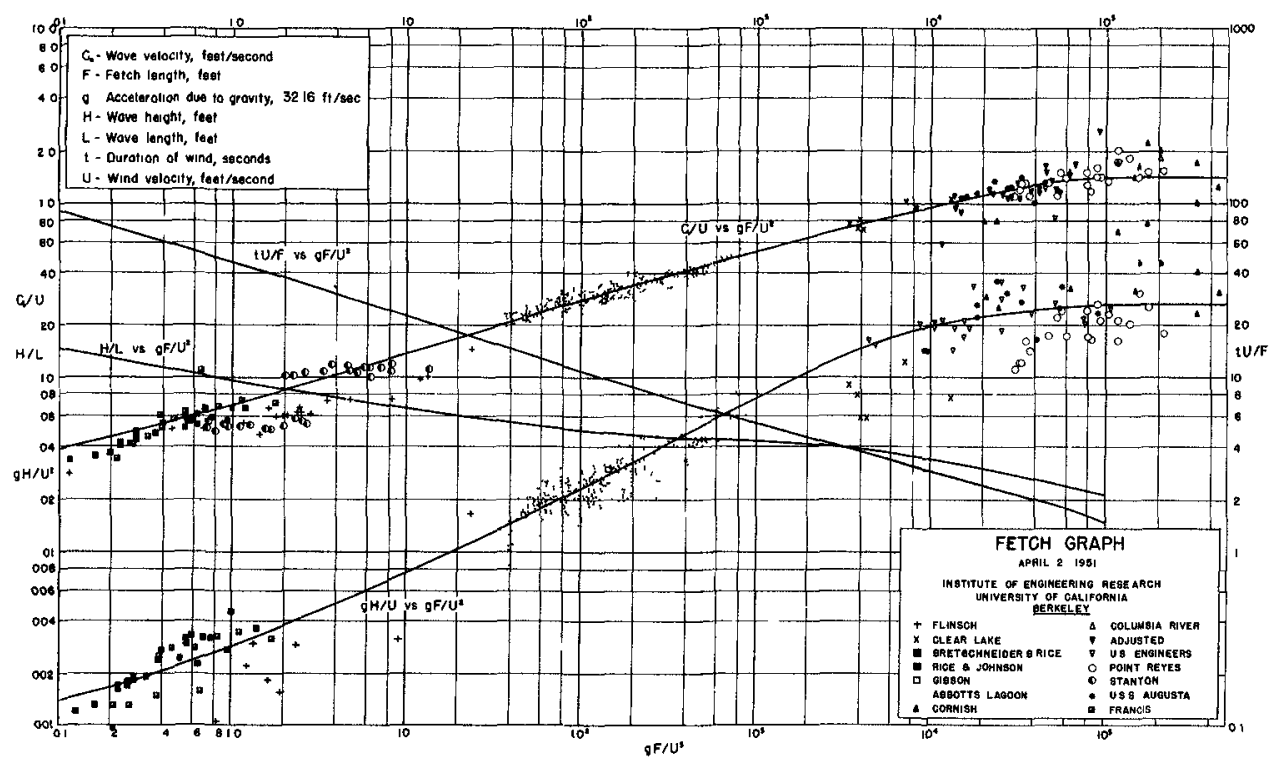

Figure 1 Fetch Graph - Relationship between Wind Speed, Wind Duration, Fetch, Wave Height, and Wave Velocity.

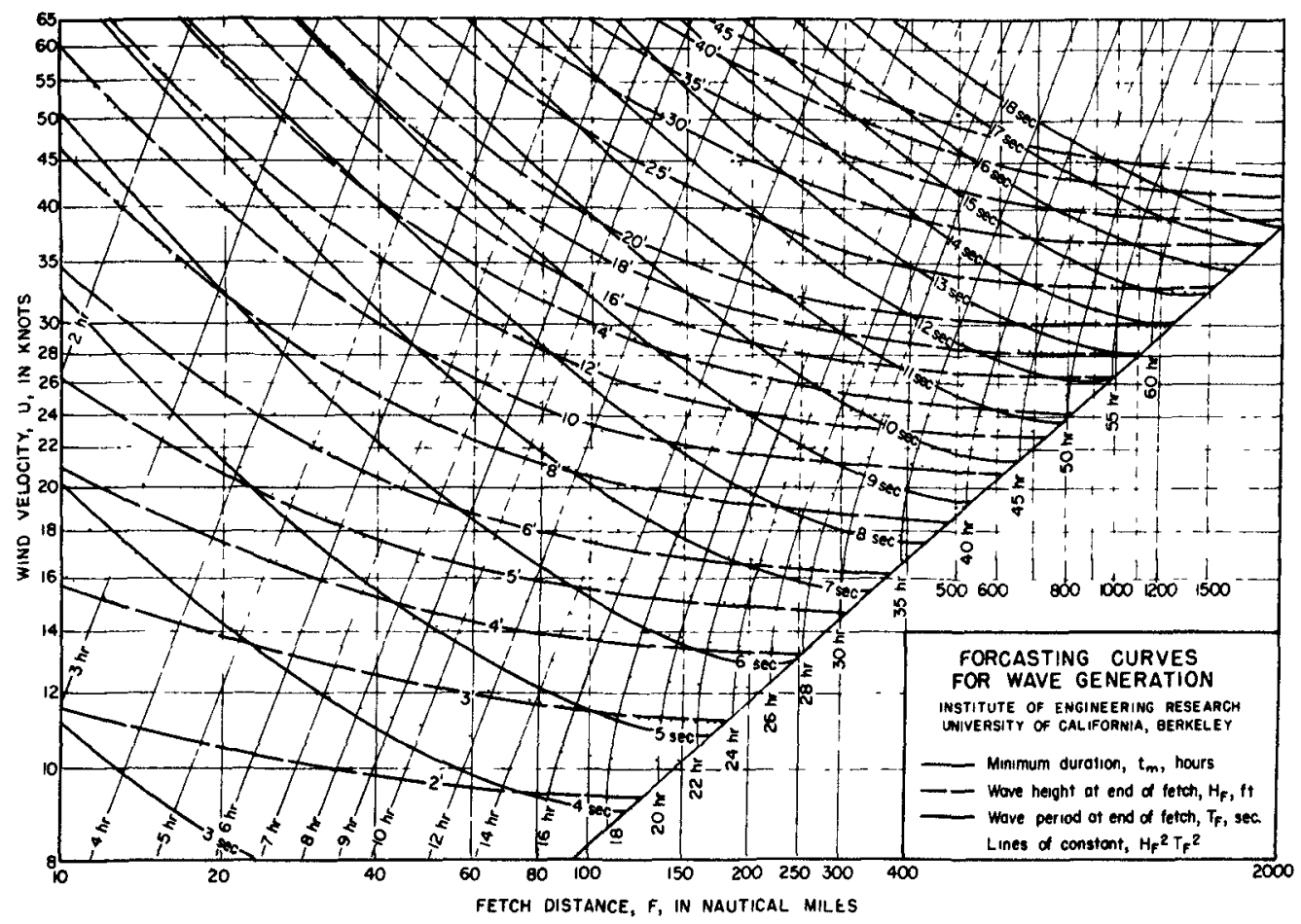

Figure 2, Forcasting Curves for Wave Generation 


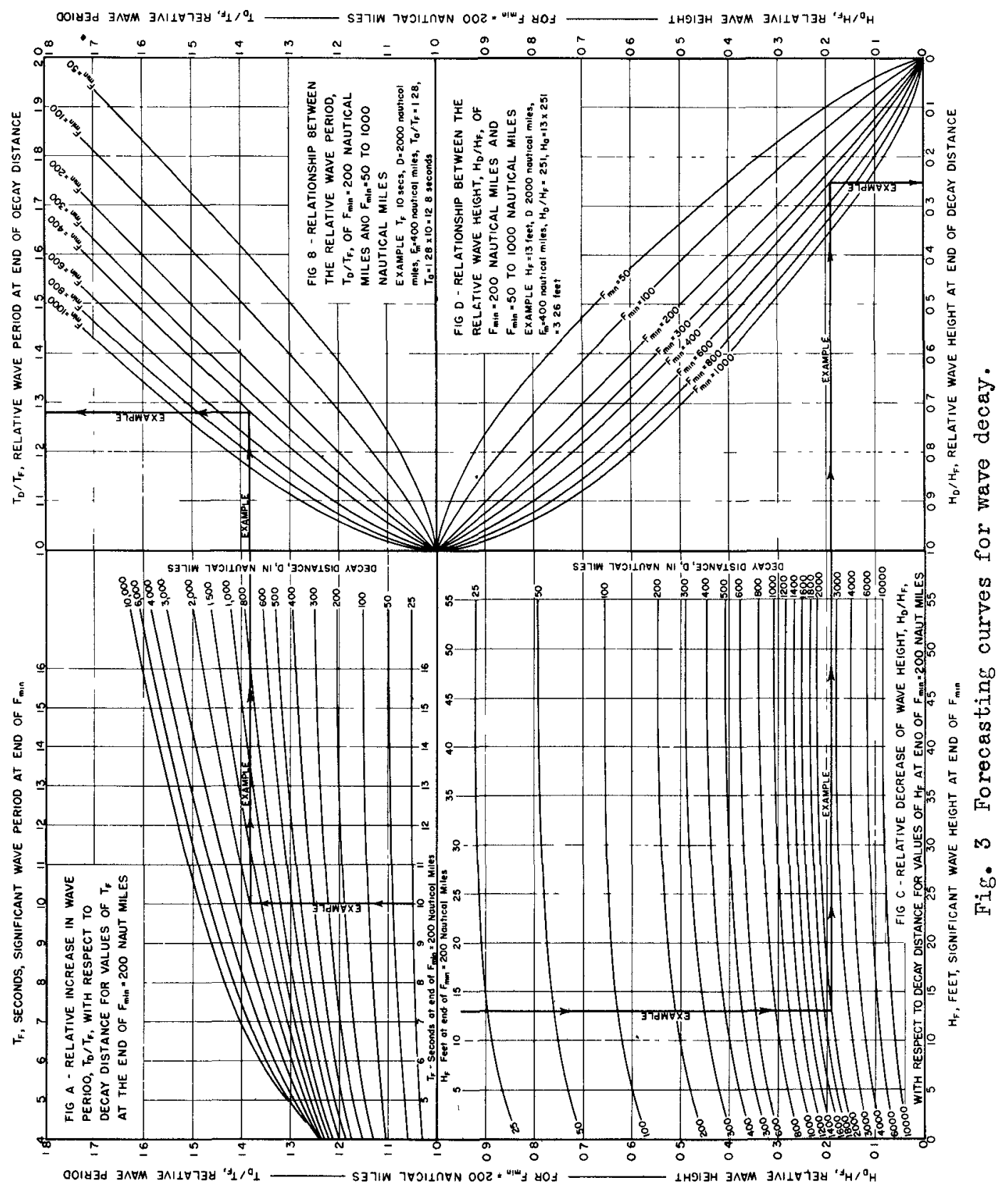


COASTAL ENGINEERING

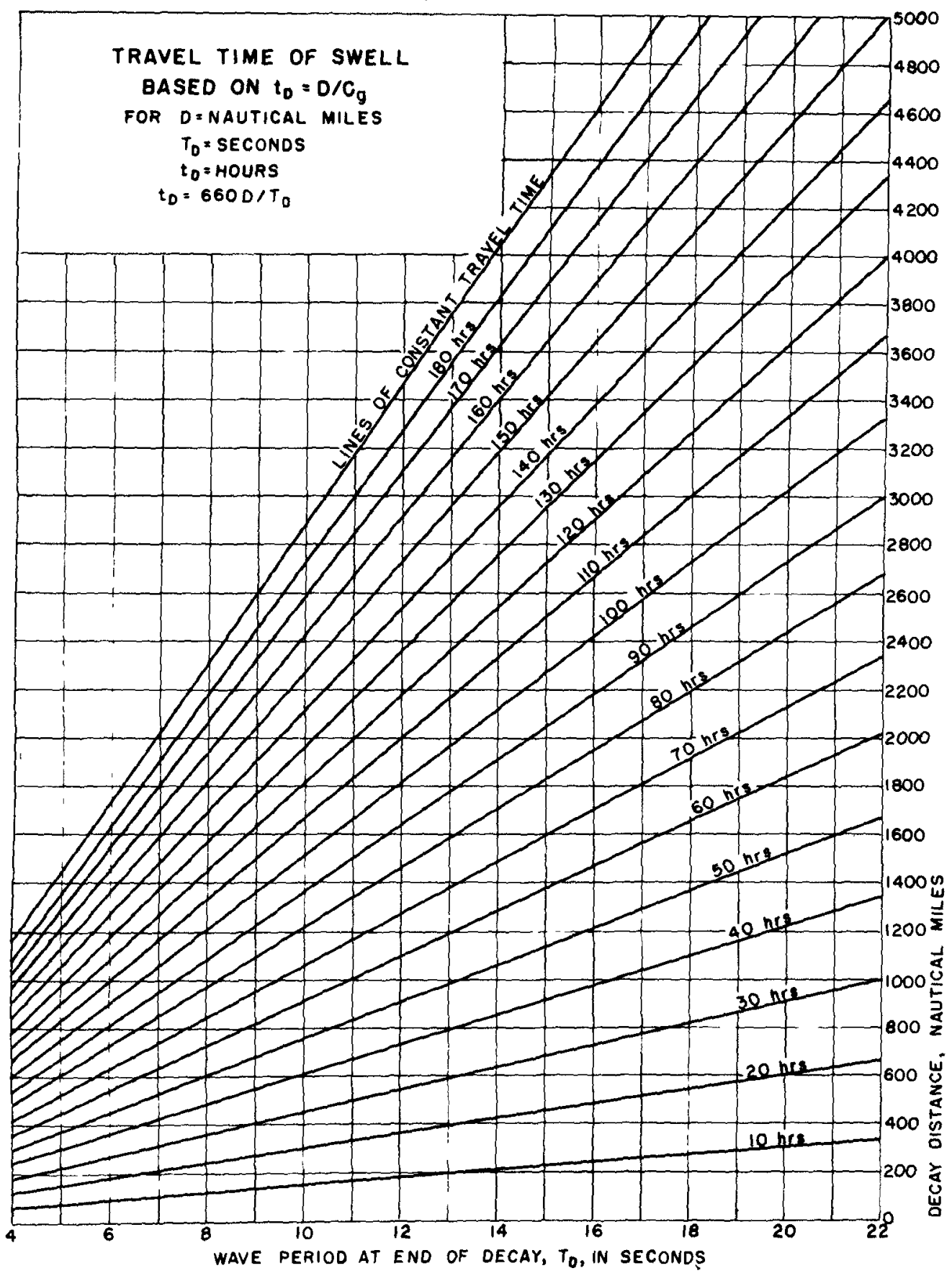

Fig. 4

Travel time of swell - Relationship between travel time, decay distance and wave period at end of decay. 
Forecasting Curves: Figure 2, forecasting curves for the generation of waves, is prepared from Figure 1. Figure 3, forecasting curves for the decay of wares, is prepared from published decay curves (Bretschnoider, 1951). Since Figures 2 and 3 are based on much wave data, they may be used to make reliable wave forecasts.

The travel time of the swell is based on the average group velocity of the significant waves at the end of decay and is given in Figure 4.

Example of the use of Figures 2 and 3

Given: $\quad U=23.5$ knots (as determined from weather map)

$F=600$ nautical miles (as measured from weather map)

$t_{d}=33$ hours (as determined from weather map or maps)

$D=2000$ nautical miles (measured from weather maps)

Enter Figure 2 at the left on $U=23.5$ knots and proceed until either $t_{m}=33$ hours or $F=600$ nautical miles is first reached, and read $F_{F}=$ 13 feet, $T_{F}=10$ seconds, $t_{m}=33$ hours and $F=400$ nautical miles (this is $F_{\min }^{*}$ )

Enter Figure 3-A at $T_{F}=10$ seconds, and proceed to decay, $D=2000$ nautical miles (this $\frac{F}{\mathrm{f}}$ ives $\mathrm{T}_{\mathrm{D}} / \mathrm{T}_{\mathrm{F}}$ at $\mathrm{D}=2000$ nautical miles for a significant wave period at the end of fetch (minimum fetch) of 200 nautical miles). Proceed horizontally to Figure $3-B$ to $F=400$ nautical miles and read $T_{D} / T_{F}=1.28 ; T_{D}=10 \times 1.28=12^{m} .8 \mathrm{sec}$.

To determine the wave height, $\mathrm{H}_{D}$ at the end of the decay curres, use Figure 3-C and $D$, and read $\mathrm{H}_{\mathrm{D}} / \mathrm{H}_{F}=0.25 ; \mathrm{H}_{\mathrm{D}}=3.3$ feet.

From Figure 4, the travel time of the swell is $t_{D}=103$ hours.

\section{References}

Bretschneider, C.L. (1951). The Generation and Decay of Wind Generated Gravity Waves: Tras. Amer. Goophys. Union (In press)

Sverdrup, H. U. and Munk, W. H. (1947). Wind, sea, and swell; Theory of relation for forecasting: Hydrographic office, U. S. Navy, Publ. No. 601 .

\footnotetext{
*For a given wind velocity the fetch length behind which a steady state is reached depends only upon the wind duration. For a given duration of wind this steady state fetch depends on the wind velocity and is shorter for weak winds than strong winds. This fetch length is called minimum fetch, $F_{\min }$
} 